\title{
The influence of d-amphetamine, benactyzine, and chlorpromazine on performance in an auditory vigilance task'
}

\author{
M. LOEB, G. R. HAWKES ${ }^{2}$, W. O. EVANS ${ }^{3}$, AND E. A. ALLUISI ${ }^{4}$ \\ U. S. ARMY MEDICAL RESEARCH LABORATORY, FORT KNOX, KENTUCKY
}

\begin{abstract}
Detections, false responses, and latencies were measured in a 1-hr. auditory vigilance task following ingestion of either a stimulating drug, one of two tranquilizers, or a placebo. Changes in performance under the placebo were explicable in terms of shifts toward conservatism in S's criteria for responding; under the tranquilizers, similar shifts in criteria occurred as well as decrements in effective sensitivity. Under the stimulant, performance quality remained essentially constant during the $1-\mathrm{hr}$. vigil.
\end{abstract}

\section{Problem}

Generally it has been reported that stimulating psychotropic drugs improve watchkeeping (Mackworth, 1950; Payne \& Hauty, 1954; Kornetsky et al, 1959). The influence of tranquilizers and depressant drugs on vigilance has not been well established: Payne \& Hauty (1954) found that hyoscine impaired performance, but Bakan (1961) found that meprobamate had little effect.

None of these studies employed a task likely to produce an appreciable number of false positive responses as well as detections. Yet the use of such tasks (e.g., nonverbal auditory signals relatively difficult to discriminate) might provide more sensitive measures of drug effects. It has been suggested (Egan et al, 1961) that vigilance performance may result from changes in S's criteria for responding rather than from changes in effective sensitivity. Recent experiments using auditory tasks support this view (Broadbent \& Gregory, 1964) Loeb \& Binford, 1964); performance changes in a visual task, however, have been attributed partly to changes in sensitivity (Mackworth \& Taylor, 1963).

In the present study, vigilance performance on a nearthreshold auditory task was measured after ingestion of a stimulating drug, (d-amphetamine), a tranquilizer primarily sympatholytic in its central effects (chlorpromazine; see Jacobsen, 1960), a parasympatholytic tranquilizer (benactyzine), or a placebo.

\section{Method}

Twenty-four paid male and female students ranging in age from 17 to 28 years served as Ss. Each continuously monitored the same auditory display for four 60 -min. sessions on each of four different days. An hour before each session each $S$ swallowed one of four capsules, identical in appearance, containing either benactyzine hydrochloride $(2 \mathrm{mg})$, dextro-amphetamine sulphate $(10 \mathrm{mg})$, chlorpromazine hydrochloride $(50 \mathrm{mg}$ ), or a placebo (lactose, $100 \mathrm{mg}$ ). The order of conditions was partially counterbalanced across Ss.

The auditory display was a train of random noise pulses, $60 \mathrm{db}$ above threshold, $0.5 \mathrm{sec}$. in duration, initiated at 2.5 - sec. intervals, with an occasional pulse $62.1 \mathrm{db}$ in intensity. The auditory stimuli were generated by the output of a General Radio random noise generator fed through timing circuits into Permoflux earphones imbedded in Willson earmuffs. Ambient noise level in the experimental room was approximately $40 \mathrm{db}$. S was instructed to respond to the 62.1 $\mathrm{db}$ pulses (hereafter termed signals) by releasing a key. Signals were programmed randomly at intervals ranging in 30 -sec. steps from 60 to 180 sec., with a mean of $120 \mathrm{sec}$.

Responses within $2 \mathrm{sec}$. of signal termination were scored as detections, and latencies (in $\mathrm{msec}$.) for such detections were recorded from a Standard Electric Timer. Responses at other times were scored as false positive responses.

\section{Results}

The percentage of detections (responses to one of the 10 signal pulses) is shown as a function of the percentage of false positives (responses to one of the 470 nonsignal pulses) under each drug condition in Fig. 1; each point is for a 20-min. block of time. The ordinate and abscissa are also given in unit normal deviates.

If the signal and signal-plus-noise distributions are equal in variance, and if the criteria for responding shift with time with no change in effective sensitivity, all the points should lie along a line with unit slope (as shown in the figure); such results have been obtained elsewhere (Loeb \& Binford, 1964). The data of Fig. 1 suggest that the points for the placebo and benactyzine groups may fall along lines with unit slope.

Detection and false response differences between the first and last blocks of trials within each drug condition were analyzed with the Wilcoxen-T test; differences across treatments for each 20-min. block were analyzed with the Friedman nonparametric analysis of variance.

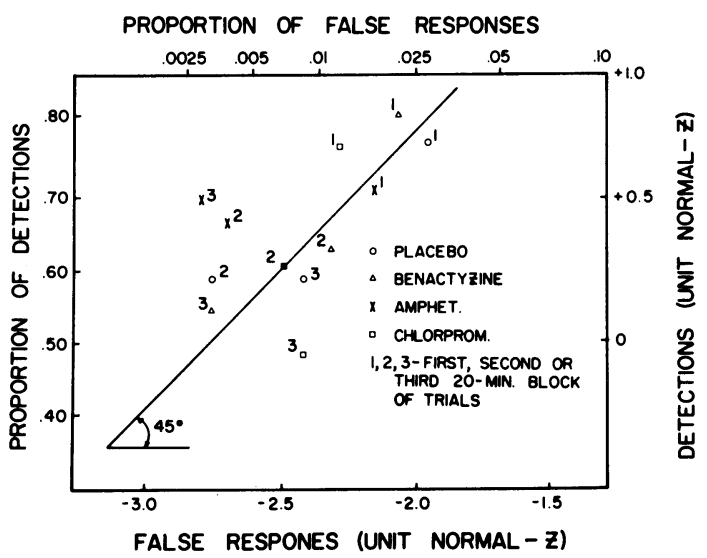

Fig. 1. Receiver Operating Characteristic (ROC) Curves for each of four drug conditions based on three 20-min. blocks of time. 
Effective-sensitivity and degree-of-conservatism scores ( $\alpha^{\prime}$ and $\beta$, in detection theory terms) were computed for each S's three blocks of trials (for methodology see Broadbent \& Gregory, 1963) and analyzed like the detections and false responses.

Findings may be summarized as follows: Detections declined significantly $(p<.01)$ under the influence of placebo, chlorpromazine, and benactyzine; the small decrement observed under the stimulant, d-amphetamine, was not statistically significant. False responses declined significantly between the first and third block of trials under each condition $(p<.01)$, but differences among drug conditions generally fell short of significance. Effective sensitivity (d') decreased significantly $(p<.05)$ under each tranquilizer, but not under the placebo or stimulant. The index of conservatism $(\beta)$ increased significantly $(p<.05)$ under each condition except the stimulant, $d$-amphetamine. Differences in $d^{\prime}$ and in $\beta$ across drugs fell short of significance, except in the third block of trials where d' was significantly $(p<.05)$ greater under $d$-amphetamine.

Response latencies were analyzed similarly. Mean latencies ranged from 0.64 to $0.76 \mathrm{sec}$., increasing between the first and third block of trials under each condition. The increases were statistically significant $(p<.05)$ under each condition except the stimulant. Overall differences across conditions were significant only within the third block of trials $(p<.02)$.

\section{Diseussion}

In general, the data indicate that the change in performance under the control (placebo) condition is ascribable principally to a shift in the criteria for responding $(\beta)$-in the direction of greater conservatism-rather than to a decline in effective sensitivity (d'). This shift is also noted under the two tranquilizer conditions, but there is apparently also a decline in effective sensitivity under these conditions. There is apparently a tendency for performance to remain relatively constant under the stimulant (d-amphetamine) condition. The latency increases observed in all conditions except the stimulant might be attributed either to increased conservatism, or decreased sensitivity, or to both factors acting together (in the case of the tranquilizers). Interestingly, two tranquilizers of different chemical classes (viz., a phenothiazine and a diphenylmethane) produced similar effects here, but in other situations they have shown different physiological and behavioral effects (Bradley, 1963; Sherrod, 1963).
Similar results might not be obtained with a typical visual monitoring task (e.g., the Mackworth clock task) where the observing response-the physical orientation of the subject toward the display-has important consequences for signal detection. Mackworth \& Taylor (1963) report changes in $d^{\prime}$ as well as $\beta$ in a visual vigilance-like situation, and Weiner \& Ross (1962) report that d-amphetamine generally increases the number of observing responses. Thus, it might be expected that stimulating drugs will have greater enhancing effects and tranquilizers greater decremental effects on visual watchkeeping than on aural watchkeeping. This expectation remains to be verified empirically.

\section{References}

Bakan, P. Effect of meprobamate on auditory vigilance. Percept. mot. Skills, 1961, 12, 26.

Bradley, P. B. Phenothiazine derivatives. In W. S. Root and F. G. Hofmann (Eds.), Physiological pharmacology. New York: Academic Press, 1963.

Broadbent, D. E., \& Gregory, M. Vigilance considered as a statistical decision. Brit. J. Psychol., 1963, 54, 309-323.

Egan, J., Greenberg, G. Z., \& Schulman, A. I. Operating characteristics, signal detectability, and the method of free response. J. acoust. Soc. Amer., 1961, 33, 993-1007.

Jacobsen, E. The comparative pharmacology of some psychotropic drugs. Bull. WHO, 1960, 21, 411-493.

Kornetsky, C., Mirsky, A. F., Kessler, E. D., \& Dorff, J. E. The effects of dextro-amphetamine on behavioral deficits produced by sleep loss in humans. J. Pharmacol., 1959, 127, 46-50.

Loeb, M., \& Binford, J. R. Vigilance for auditory intensity changes as a function of preliminary feedback and confidence level. Hum. Factors, 1964, 6, in press.

Mackworth, J. F., \& Taylor, M. M. The d' measures of signal detectability in vigilance-like situations. Canad. J. Psychol., 1963, $17,302-325$.

Mackworth, N. H. Researches on the measurement of human performance. London: H. M. Stationery Office, 1950.

Payne, R. B., \& Hauty, G. T. The effects of experimentally induced attitudes on job proficiency. J. exp. Psychol., 1954, 47, 267-273.

Sherrod, T. R. Diphenylmethane derivatives. In W. S. Root and F. G. Hofmann (Eds.), Physiological pharmacology. New York: Academic Press, 1963.

Weiner, H., \& Ross, S. The effects of "unwanted" signals and d-amphetamine sulphate on observers' responses. J. appl. Psychol., 1961, 46, 135-141.

\section{Notes}

1. This research was aided by an Army Medical $R \& D$ contract with the University of Louisville. The assistance of Dr. J. R. Binford, C. F. Gettys, and W. H. Williams, Jr., is gratefully acknowledged. 2. Now at U. S. Army Medical R \& D Command.

3. Now at U. S. Army Medical Research and Nutrition Laboratory. 4. Now at University of Louisville. 